\begin{tabular}{|c|c|c|}
\hline $\begin{array}{l}\text { PUCRS } \\
\text { PUC. }\end{array}$ & $\begin{array}{l}\text { ESCOLA DE } \\
\text { HUMANIDADES }\end{array}$ & $\begin{array}{l}\text { Revista Digital do Programa de Pós-Graduação em Letras da PUCRS } \\
\text { Letrônica, Porto Alegre, v. 13, n. 1, p. 1-11, jan.-mar. } 2020 \\
\text { e-ISSN: } 1984-4301\end{array}$ \\
\hline de) $\mathrm{http}: / / \mathrm{dx}$ & org/10.15448/1984-4301.2020.1.35139 & \\
\hline
\end{tabular}

\title{
A escrita feminina em La casa de los espíritus, de Isabel Allende
}

\author{
The feminine writing in La casa de los espiritus, by Isabel Allende \\ La escrita femenina en La casa de los espiritus, de Isabel Allende
}

\section{Amanda da Silva \\ Oliveira $^{1}$ \\ orcid.org/0000-0003-3793-1450 \\ amanda.oliveira@ufsm.br}

Recebido em: 31 jul. 2019.

Aprovado em: 7 nov. 2019.

Publicado em: 7 abr. 2020
Resumo: A obra La casa de lo sespiritus, de Isabel Allende, corresponde a uma importante narrativa de escrita de mulheres latino-americanas. Publicada em 1982 faz parte do pós-boom, movimento que atualiza a escrita do boom latino-americano para determinadas caracteristicas literárias, como o memorialistico. O objetivo deste artigo é analisar a obra de Allende a partir da (re)escritura que a personagem Alba faz da história da família como modo de recuperar a si mesma como sujeito. A escrita da memória de Alba significa os novos rumos da literatura latino-americana pós-boom: uma escrita para não esquecer. Por fim, conclui-se desenvolvendo brevemente de que maneira La casa dos espiritus serve como um texto que reforça o papel feminista de empoderamento da mulher, por meio da escrita.

Palavras-chave: Escrita feminina. Literatura latino-americana. Memória. Poder. Gênero.

Abstract: Isabel Allende's La casa de los espiritus is an important writing narrative of Latin American women. Published in 1982, it is part of the post-boom movement that updates the writing of the Latin American boom to certain literary characteristics, such as the memoir. The purpose of this article is to analyze Allende's work from the (re)writing that character Alba makes of her family's history to recover as herself. The writing of Alba's memories represents the new directions of post-boom Latin American literature: writing in order to never forget. Finally, it is concluded by briefly developing how La casa dos espiritus acts as a text that reinforces the feminist role of empowering women through writing.

Keywords: Feminine writing. Latin American literature. Memory. Power. Gender.

Resumen: La obra La casa de los espíritus, de Isabel Allende, corresponde a una importante narrativa de escrita de mujeres latinoamericanas. Publicada en 1982, hace parte del post Boom, movimiento que actualiza la escrita del Boom latinoamericano para determinadas características literarias, como el memorialístico. El objetivo de este artículo es analizar la obra de Allende a partir de la (re) escritura que el personaje Alba hace de la historia de la familia como modo de recuperar a si misma como sujeto. La escrita de la memoria de Alba significa los nuevos rumbos de la literatura latinoamericana postBoom: una escrita para no olvidar. Por fin, se concluye desarrollando brevemente de qué manera La casa de los espíritus sirve como un texto que refuerza el papel feminista de empoderamiento de la mujer, por medio de la escrita.

Palabras clave: Escrita femenina. Literatura latinoamericana. Memoria. Poder. Género. 


\section{Considerações iniciais: uma questão de conceito}

Em 2007, a extinta revista Bravo! publicou uma matéria sobre a popularidade que os nomes da literatura latino-americana, como Gabriel Garcia Márquez e Mario Vargas Llosa, estavam alcançando no Brasil, com a obra do peruano sendo completamente reeditada no País pela editora Alfaguara. Com o título "A nova onda latina", a matéria da Bravo!, assinada por Oscar Pilagallo, destacava que "a literatura latino-americana não é uma coisa só" (2007, p. 22), e que "esse novo 'boom' literário também tem o mérito de apresentar ao leitor brasileiro uma nova geração de talentos e resgatar mestres precursores, que só recentemente foram descobertos no país" (2007, p. 27).

Na matéria, foram destacadas quatro vertentes do Boom latino-americano: realismo mágico/universo rural; existencialismo; fantástico e experimental e realismo/universo urbano. Isabel Allende, segundo a definição da Bravo!, localiza-se no galho do realismo mágico/universo rural, uma "mescla de realismo rural com visão de mundo mágico" (2007, p. 25). La casa de los espiritus apresenta os temas da ruralidade, como a propriedade de Esteban Trueba, e o mundo mágico da casa da esquina, com as inúmeras visitas de personalidades deste e do outro mundo de Clara Trueba.

Considerada na matéria como a primeira mulher de destaque do Boom (2007, p. 25), Isabel Allende configura um espaço de escritura feminina que alia elementos de sua vivência pessoal com as vivências da história das Américas. É por meio de seu livro que identificamos alguns elementos importantes para a composição da escritura feminina, aqui proposta: a representação da escrita como processo de empoderamento e de reconstrução do sujeito feminino.

O mais interessante dessa informação, no entanto, está fora do contexto das páginas da revista. Em um interesse em divulgar as melhores narrativas do movimento, esqueceu-se, ou escondeu-se, um dado bastante curioso sobre Isabel Allende e sua literatura no contexto dos artistas do Boom. Para Donald Shaw, durante el Boom empezó a manifestarse lo que más tarde llegó a llamarse 'una crisis de representación', dada la tendencia de ciertos escritores del Boom a cuestionar su propia capacidad de observar, describir e interpretar la realidad mediante el empleo acrítico del lenguaje referencial (SHAW, 1999, p. 253).

A escritura que passa a significar o "más indicado para explicar lo que quiere decir ser um latinoamericano" (SHAW, 1999, p. 253), nas palavras de Victoria Ocampo, desenvolve-se por meio da característica da memorialística, de cunho testemunhal. Dessa forma, sinaliza Shaw: "el testimonio señala el final del Boom, pero donde vemos mejor sus manifestaciones es en los textos escritos por mujeres" (SHAW, 1999, p. 253).

Dessa forma, a Literatura testemunhal passa a ocupar um importante espaço na história da literatura hispano-americana entre o final dos anos 1970 e início dos anos 1980, porque, diferente dos aspectos experimentais e existenciais do sujeito no mundo, nas questões sobre as percepções da realidade, próprias do Boom, "la separación entre nosotros y 'lo otro' no tiene que ver con la metafísica ni con nada inherente a la condición humana, sino que es el resultado de una lucha por el poder económico, social y político" (SHAW, 1999, p. 258).

Shaw indica que o "incuestionable triunfo" (1999, p. 260) do movimento conhecido como pós-Boom é La casa de los espiritus, de Isabel Allende. Para o autor, "el Boom fue un movimiento de autores masculinos, en el que no entraron escritoras conocidas como Rosario Castellanos - Beatriz Guido, que eran sus contemporáneas" (1999, p. 260). O movimento, apesar de reunir um certo grupo de autores "que tenían um innegable aire de familia" (SHAW, 1999, p. 260), marginalizou muitos outros autores cuja escrita apresentava tendências diferentes. Para Shaw,

\begin{abstract}
las fuerzas centripedas de la narrativa hispanoamericana que fueron algo opacadas por el éxito del Boom estallaron en los años 70. Sin duda, la novedad más visible fue la entrada en la escena de un grupo numeroso de escritoras desde Isabel Allende hasta Laura Esquivel - que exploró nuevos rumbos (SHAW, 1999, p. 260).
\end{abstract}

A diferença entre as duas correntes se torna clara quando Shaw afirma que "en la narrativa 
del Boom, cabe repetirlo, el amor nunca, o muy rara vez, contribuye a que los personajes se reconcilien con su situación existencial" (SHAW, 1999, p. 262), no pós-Boom ocorre o que a própria Isabel Allende explica:

en la actividad frente al amor somos más optimistas... Hay una especie de renovación... yo diría del romanticismo, del amor, de los sentimientos, de la alegria de vivir, de la sensualidad. Y una posición mucho más optimista frente al futuro y vida (ALLENDE, 1991 apud SHAW, 1999, p. 262).

Os escritores e as escritoras do movimiento são "gente más esperanzada" (SHAW, 1999, p. 262), já que "en la literatura del posboom, no hay resignación ni pesimismo" (SHAW, 1999, p. 262). A obra de Allende, por exemplo, significa ao pósBoom o que Cien años de soledad representa ao Boom, e é considerado "el acontecimiento literario más memorable de principios de los años 80 en Hispanoamérica" (SHAW, 1999, p. 277).Essa importância histórica do que a obra de Allende se tornou para o novo movimento que então se destacava representou um também importante impulso ao movimento feminista latino-americano.

As escritoras passam a ter espaço na nova concepção de produção literária da cultura hispano-americano. Na obra de Allende, o feminismo é elemento característico, presente e reconhecivel como questão social importante das obras escritas pelas mulheres. Os destaques das personagens Clara e Alba, no que tange à escritura, são intencionalmente representativos da transgressão feminina, pois "ambas conciben el escribir como unacto de resistência contra una sociedade opresiva" (SHAW, 1999, p. 280), movimento que amplia o sentido da escrita como não só feminina, mas feminista, Segundo as palavras da própria autora:

Elegi mujeres extraordinarias, capaces de simbolizar mi visión de lo que significa lo femenino, personajes que podian ilustrar el destino de lãs mujeres em Latinoamérica... todas lãs mujerese $\mathrm{n}$ mi novela son feministas de una manera $u$ outra (ALLENDE, 1984 apud SHAW, 1999, p. 280).

Partindo desse pressuposto, é importante pensar como os discursos literários produzidos pelas mulheres podem contribuir para essa tomada de posição social do espírito de representatividade da América Latina, e como esses discursos colaboram para o desenvolvimento da cultura identitária latino-americana de ser quem é. A literatura feita por mulheres a partir dos anos 1980, aqui destacado pela obra de Isabel Allende, configura a intencionalidade da reescrita da história oficial, tornando a história mais que uma única verdade, escrita por homens: uma possibilidade de tornar múltipla a narrativa que constrói a identidade do povo latino-americano.

\section{Uma questão de análise}

Para Ricoeur, a imagem, a eikõn, como objeto da memória, é a presença de algo ausente (2007. p. 18), que representa o passado, pois "dizemos instintivamente que nós representamos um acontecimento passado, ou que temos dele uma imagem, que pode ser quase visual ou auditivo" (RICOEUR, 2007, p. 25). Apesar de não totalmente fidedigna, e por vezes pouco confiável, o autor afirma que essa imagem que fazemos do passado ainda é o único recurso pelo qual podemos nos permitir caracterizá-lo.

Dessa forma, o esquecimento, "sombra da região iluminada da memória" (RICOEUR, 2007, p. 40), é o que pode ser olvidado nos relatos e nas construções de um passado pelo sujeito. Como maneira de se constituir, a lembrança do passado é o como já foi se torna o como é, em que

\begin{abstract}
A busca da lembrança comprova uma das finalidades principais do ato de memória, a saber, lutar contra o esquecimento, arrancar alguns fragmentos de lembrança à "rapacidade" do tempo (Santo Agostinho dixit), ao "sepultamento" no esquecimento. Não é somente o caráter penoso do esforço de memória que dá à relação sua coloração inquieta, mas o temor de ter esquecido, de esquecer de novo, de esquecer amanhã de cumprir esta ou aquela tarefa; porque amanhã será preciso não esquecer... de se lembrar (RICOEUR, 2007, p. 48).
\end{abstract}

Por meio da "experiência anteriormente adquirida" (RICOEUR, 2007, p. 43), os valores do memorialístico tomam forma e, para o autor, o "dever da memória consiste essencialmente em dever de não esquecer" (RICOEUR, 2007, p. 48). 
Esse dever encontra-se no testemunho, termo que "constitui a estrutura fundamental de transição entre a memória e a história" (RICOEUR, 2007, p. 41). Para Ricoeur, o testemunho se configura como um dos processos do desejo de manutenção memorialistica, em que "nos leva, de um salto, das condições formais ao conteúdo das 'coisas do passado', das condições de possibilidade ao processo efetivo da operação historiográfica" (RICOEUR, 2007, p. 170), feito memória arquivada quando escrito, em que "a composição da trama de uma história contada vem, além disso, reforçar a autonomia semântica de um texto, à qual a composição em forma de obra proporciona a visibilidade da coisa escrita" (RICOEUR, 2007, p. 176).

Assim, a testemunhal escritura que se forma em La casa de los espíritus evidencia uma narrativa que inicialmente já apresenta uma voz de alguém que se coloca necessitada de registros escritos não só para manutenção de um passado, para a visibilidade da escrita, como referido por Ricoeur, mas para, principalmente, sobreviver. Já nas primeiras linhas da história, temos a presença de um narrador, ainda não identificado, que deixa evidente a intencionalidade dessa reminiscência como único modo de construção de si mesmo como sujeito, ao que esse narrador chama de resgate e sobrevida:

Barrabás llegó a la familia por vía marítima, anotó la niña Clara con su delicada caligrafia. Ya entonces tenía el hábito de escribir las cosas importantes y más tarde, cuando se quedó muda, escribia también las trivialidades, sin sospechar que cincuenta años después, sus cuadernos me servirian para rescatar la memoria del pasado y para sobrevivir a mi propio espanto (ALLENDE, 2015, p. 11).

Barrabás, o enorme cachorro, que chega em uma jaula suja dos próprios excrementos, é apenas um filhote quando Clara é criança, longe da imagem de gigante legendario que llegó a ser. A imagem do animal, quase atrelada a de um animal fantástico - não esqueçamos que ele chega em Jueves Santo -, é apenas o ponto de inflexão com que a autora insere a narrativa, que surge como das anotações de Clara - nesse instante ainda menina - e como a forma de, resgatando o passado, salvar a vida desse alguém que "fala", que se utiliza desses apontamentos importantes e triviais em um passado não vivido para se constituir, por meio dessa memória escrita.

Ao longo da narrativa, vamos identificando essas vozes narrativas. Há um discurso em primeira pessoa protagonizado por Esteban Trueba, noivo de Rosa, a bela, mas que acaba por ser marido de Clara; e em terceira pessoa, que conta a história da família, adotando a voz em primeira pessoa em alguns momentos, quando, temporalmente, faz parte da história: a neta de Esteban e Clara, Alba.

A primeira cena, da missa de domingo, aliada à chegada do corpo do tio Marcos, revela o fio condutor de toda a narrativa: as relações espirituais serão constantemente relacionadas às escolhas das personagens, e os mundos real e espiritual estarão em igualdade. Se o destino geralmente é entendido como uma sucessão inevitável de ocorrências relacionada a uma ordem cósmica, as mulheres dessa familia terão o poder de nessa ordem se infiltrar.

O mal-estar sentido por Nivea na missa se mesclava com as palavras do sermão do Padre Restrepo, que anunciava em seu discurso a incompreensão de igualdade de direitos, confundida como pecaminosos atos:

fariseos que pretendian legalizar a los bastardos y al matrimonio civil, desarticulando a lafamilia, lapatria, lapropiedad y La iglesia, dando a las mujeres la misma posición que a los hombres, en abiertos desafíos a La ley de Dios, que enese aspecto era muy precisa (ALLENDE, 2015, p. 13).

Dizer que os direitos das mulheres correspondem a um desafio às leis de Deus é uma forma de o discurso narrativo comprovar o status quo que o espaço social chileno apresentava naquele período. Nívea é um demônio, bem como a filha, Clara, que afronta as palavras do padre com um comentário infantil: "iPst! iPadre Restrepo! Si el cuento del infierno fuera pura mentira, nos chingamos todos..." (ALLENDE, 2015. p. 17), ao que o sacerdote grita: "iEndemoniada! iSoberbia endemoniada!" (ALLENDE, 2015, p. 17).

A única mulher da familia com uma imagem diferenciada é Rosa, "la bella", que, "con su extraña belleza tenía una cualidad perturbadora de la cual 
ni ella escapaba, parecia fabricada de un material diferente al de la raza humana"(ALLENDE, 2015, p. 14), sendo "un ser celestial, que no estaba hecho para durar mucho tiempo en el tráfico grosero de este mundo"(ALLENDE, 2015, p. 16). Santa ou demônia, a figura da mulher demonstra os paradigmas religiosos como impositores e definidores das representações femininas, nos contextos sociais que, em nome de Deus, condena as mulheres aos papéis subalternos e discriminatórios.

Clara mostrava, ainda na infância, um poder com o oculto e com a mística, longe das necessidades sociais da realidade, mas também não totalmente pertencente ao mundo celestial, como a irmã, Rosa. Apesar de o pai não entender como o padre podia pensar que uma criança pudesse ter um peso maligno tão grande, ao acusá-la de endiabrada, todos na familia sabiam de seus poderes sobrenaturais de levitação, mas encaravam de modo normal a situação. O único que compreendia o fenômeno como especial era tio Marcos, que entendia o poder da sobrinha como algo familiar.

A menina Clara vive em um entre-lugar, o que Ihe dá caráter de não pertencimento a nada, somente à bela casa de esquina construida pelo marido, Esteban Trueba, anos depois, ou pela ajuda aos que necessitavam de seus cuidados, sem as personificações deste ou do outro mundo. Há sempre uma atmosfera dupla nos eventos narrativos da obra, mantendo presente um caráter fantástico no texto, mas que não determina a compreensão da obra, pois não ficamos à mercê da realidade ou do fantástico. Entendem-se os dois, na justa medida dos acontecimentos.

La casa de los espiritus alia a construção social e ideológica do Chile como pano de fundo das realidades da familia Trueba. É na saga familiar das mulheres, sobretudo, que as relações entre público e privado e as questões de gênero vão se delineando. Se, de um lado, Esteban Trueba representa o autoritarismo das classes altas do Chile, Clara corresponde à cultura, à imaginação, às mestiçagens e as regionalidades, à arte, à palavra. É no discurso de Trueba que temos a narrativa construida de Alba, mas é nas consultas dos "cadernos de anotar a vida" de Clara que a neta se constrói e se define como ser.
As ambiguidades entre o campo e a cidade, a luta de classes, as certezas e as incertezas ideológicas, o amor e o desejo são elementos comuns e partícipes da narrativa, em que a redenção/salvação da personagem Alba se dá por meio da palavra. Dentro de um cenário em que o espiritual tem tanta força e sentido quanto o material, Clara é a personagem que equilibra a família e amarra a história, desde sua infância exótica sem palavras, até a escritura dos cadernos ao longo da vida, passando pela cumplicidade do amor da filha pelo filho do capataz da estância, até o sentimento renegado que tem pelo marido, uma distância corporal necessária em nome da vivência entre dois mundos.

Clara é o centro da narrativa, é ela quem mobiliza a história e dá base para a neta se reescrever. Na infância, quando decide não mais falar, possibilita a escolha do uso das palavras para existir no mundo. A presença física da menina se torna suficiente a todos, principalmente à mãe, que aprende no silêncio da filha a compartilhar da sua presença. Justamente pelo mutismo, os registros nos cadernos se intensificam:

Llenaba incontables cuadernos con sus ano-
taciones privadas, donde fueron quedando
registrados los acontecimientos de ese tiempo,
que gracias a eso no se perdieron borrados por
la neblina del olvido, y ahora yo puedo usarlos
para rescatar su memoria (ALLENDE, 2015, p. 87).

A menina Alba vive ao lado da avó até seus sete anos, quando Clara morre. A ausência física da avó é sentida por todos, mas Clara mantém-se junto à família, apesar de estar em outro plano. No momento em que uma das irmãs Mora chega à casa da esquina, com um recado da avó, Alba tem a certeza, apesar de em um momento bastante dificil, de que Clara sempre estará ao seu lado e sempre estará zelando pelas vidas dos entes queridos, apesar das tragédias ocorridas naquela familia:

- He venido a hablar con su nieta Alba, porque
tengo un mensaje para ella de su abuela. El
senador llamó a Alba. La joven no había visto a
Luisa Mora desde que tenía siete años, pero se
acordaba perfectamente de ella. La abrazó con
delicadeza, para no desbaratar su frágil esque-
leto de marfil y aspiró con ansias una bocanada
de ese perfume inconfundible. - Vine a decirte
que te cuides, hijita - dijo Luisa Mora después 
que se hubo secado el llanto de emoción-. La muerte te anda pisando los talones. Tu abuela Clara te protege desde el Más Allá, pero me mandó a decirte que los espiritus protectores son ineficaces en los cataclismos mayores. Sería bueno que hicieras un viaje, que te fueras al otro lado del mar, donde estarás a salvo. A esas alturas de la conversación, el senador Trueba habia perdido la paciencia y estaba seguro que se encontraba frente a una andana demente. Diez meses y once días más tarde, recordaría la profecía de Luisa Mora, cuando se llevaron a Alba en la noche durante el toque de queda (ALLENDE, 2015, p. 383).

Essas mulheres não compartilham só o sentido comum de seus nomes. Elas unem forças, repartem angústias, acreditam na possibilidade de realidades melhores. Dividem a vida na grande casa da esquina, ao mesmo tempo em que os sentidos das palavras escritas, sejam pelos "cadernos de anotar a vida" de Clara, sejam pelas cartas de Clara à filha, no breve casamento e afastamento das duas. A própria narrativa a que temos acesso, na construção de uma vida nova após a tortura e a humilhação que Alba vivencia, anos depois, também é o indício da escrita como registro do que a oralidade não abarca, nem necessita. No entanto, esse período é marcado pela nova geração familiar, simbolizada por Alba, em que os não ditos são adotados, os silêncios são valorados e a solidão é uma realidade.

A relação que Blanca estabelece com a filha já ocorre nos primeiros momentos do nascimento de Alba:

Alba nació con rapidez. Jaime le quitó el cordón del cuello, la sostuvo en el aire boca abajo y de dos sonoras bofetadas la inició en el sufrimiento de la vida y la mecánica de la respiración, pero Amanda, que había leido sobre las costumbres de las tribus africanas y predicaba la vuelta a la naturaleza, le arrebató la recién nacida de las enanos y la colocó amorosamente sobre el vientre tibio de su madre, donde encontró algún consuelo a la tristeza de nacer (ALLENDE, 2015, p. 278-279).

O nascimento é a porta da vida, mas também significa a entrada do individuo no sofrimento da existência. As realidades das mulheres dessa familia seguem seus destinos, como se a própria entrada no mundo, assim como suas vivências ao longo da jornada, ambas fossem independentes da vontade humana. A partilha com o mundo espiritual proporciona amenizar os sofrimentos que as três compartem. É na ligação desse mundo cósmico, dessa mística feminina, que as mulheres ousam ser nas realidades que as oprimem.

Os espaços exigem comportamentos e atitudes daqueles que ali vivem: as mulheres atuam pelas necessidades dos ambientes nos quais circulam, não pelas obrigações de seus papéis sociais. É nesse sentido que a narrativa de Isabel Allende se coloca como um prisma do que, socialmente imposto, possa se destacar como novas possibilidades de libertação dos seres e de seus destinos, principalmente em se tratando de mulheres.

Alba cresce com a ausência da avó, no plano físico, mas a avó estará ao seu lado quando mais precisar. Ao se tornar adulta e conhecer e se apaixonar por Miguel, a neta entenderá que a corporeidade é física e desejosa, um encontro de amor e de desejo, assim como quando ela foi concebida, resultado do amor ingênuo de Blanca e Pedro. O corpo é desejo e satisfação nos encontros fortuitos entre os namorados, em um dos quartos da grande casa ou no porão, onde as lembranças e memórias da família são guardadas, em suas materialidades.

Infelizmente, o corpo de Alba passa, em virtude da violência e do desejo daquela realidade social, ou em nome da sua manutenção, a estar a serviço dos desejos e das necessidades dos outros. $O$ ódio do qual é objeto pelo também neto do avô, também vítima da violência e da necessidade de satisfação sexual dos homens nas mulheres pobres, é o reforço de uma imposição à dor e à humilhação pelas quais os homens submetem às mulheres.

A casa da esquina, ao ser invadida pelos policiais, tem apenas em Alba o desejo da vingança. Não é em Esteban, representante da elite corrupta e cheia de privilégios que a crueldade se instaura, até porque a elite não é alvo da injustiça que auxilia a manter, mas sim o orgulho do modelo de normatividade. Além de neta do dono da fazenda, Alba representa o que o general García sempre quis, mas que a sua condição, imposta pela injustiça de classe, 
não permitiu que pertencesse a ele. Não é de Esteban que ele se vinga, ou pelo menos, não é na agressão física que pode cometer com o avô que realizará as suas fantasias: é na hostilidade do corpo de Alba que a injustiça deve se justificar, é a mulher que ele ousará ferir e oprimir; é o corpo da mulher que deve servir à satisfação desse desejo de violentar:

Entonces adivinó su destino. Invocó a los espíritus de los tiempos de la mesa de tres patas y del inquieto azucarero de su abuela, a los fantasmas capaces de torcer el rumbo de los acontecimientos, pero ellos parecian haberla abandonado, porque la camioneta siguió por el mismo camino. Sintió un frenazo, oyó las pesadas puertas de un portón que se abrian rechinando y volvian a cerrarse después de su paso. Entonces Alba entró en su pesadilla, aquella que vieron su abuela en su carta astrológica al nacer y Luisa Mora, en un instante de premonición (ALLENDE, 2015, p. 422).

\section{A agressividade sofrida no corpo repercute} na alma de Alba, na lembrança da premonição ouvida, mas não seguida, na sensação de poder ter evitado aquela situação em que agora se encontrava. A tentativa de manter o treinamento ensinado pelo tio Nicolás, quando pequena, para evitar as dores que a cercavam naquele ambiente tortuoso, era insuficiente diante à vivência que ali se colocava: "Alba oíalos gritos, los largos gemidos y la radio a todo volumen. El bosque, Miguel, el amor, se perdieron en el túnel profundo de su terror y se resignó a enfrentar su destino sin subterfugios" (ALLENDE, 2015, p. 426).

A força que precisa encontrar é além da física. É no mundo espiritual que essa força será construida, pois Clara é a mensageira do verdadeiro valor de sobreviver por meio do milagre da vida, não da fatalidade da morte:

Se abandonó, decidida a terminar su suplicio de una vez dejó de comer y sólo cuando la vencia su propia flaqueza bebía un sorbo de agua. Trató de no respirar, de no moverse, y se puso a esperar la muerte con impaciencia. Asi estuvo mucho tiempo. Cuando casi había conseguido su propósito, apareció su abuela Clara, a quien había invocado tantas veces para que la ayudara a morir, con la ocurrencia de que la gracia no era morirse, puesto que eso llegaba de todos modos, sino sobrevivir, que era un milagro (ALLENDE, 2015, p. 434).
O conselho que a avó dá à neta muda a sua forma de viver aquela situação, minimizando a dor do corpo, acreditando no milagre da vida, mesmo que a morte lhe pareça a realidade mais cruel e próxima:

\begin{abstract}
Alba intentó obedecer a su abuela, pero tan pronto como empezó a apuntar con el pensamiento, se llenó la perrera con los personajes de su historia, que entraron atropellándose y la envolvieron en sus anécdotas, en sus vicios y virtudes, aplastando sus propósitos documentales y echando por tierra su testimonio, atosigándola, exigiéndole, apurándola, y ella anotaba a toda prisa, desesperada porque a medida que escribia una nueva página, se iba borrando la anterior. Esta actividad la mantenía ocupada. Al comienzo perdia el hilo con facilidad y olvidaba en la misma medida en que recordaba nuevos hechos. La menor distracción o un poco más de miedo o de dolor, embrollaban su historia como un ovillo. Pero luego inventó una clave para recordar en orden, y entonces pudo hundirse en su propio relato tan profundamente, que dejó de comer, de rascarse, de olerse, de quejarse, y llegó a vencer, uno por uno, sus innumerables dolores (ALLENDE, 2015, p. 434-435).
\end{abstract}

Clara ensina à neta o poder das palavras, mas esse poder só pode ser beneficamente utilizado se houver a percepção de seu próprio protagonismo na escrita dessa narrativa. De nada vale escrever sobre as informações que se memora se não há construção de si mesmo naquilo que se conta. As personagens não podem ocupar o centro da história escrita por Alba, pois ela é a personagem que se construirá por meio dessa narrativa. A escrita serve como forma de construção, mas, no caso de Alba, ela servirá também para que ela própria se reconstrua. Anotar as ocorrências diárias é uma tarefa levada por toda a vida da avó; agora, cabe à neta entender esse processo como algo que torna a vivência suportável e refaz a sua identidade:

Clara trajo la idea salvadora de escribir con el pensamiento, sin lápiz ni papel, para mantener la mente ocupada, evadirse de la perrera y vivir. Le sugirió, además, que escribiera un testimonio que algún día podría servir para sacar a la luz, el terrible secreto que estaba viviendo, para que el mundo se enterara del horror que ocurria paralelamente a la existencia apacible y ordenada de los que no querian saber, de los que podian tener la ilusión de una vida normal, de los que podian negar que iban a flote en una balsa sobre un mar de lamentos, ignorando, a pesar de todas las 
evidencias, que a pocas cuadras de su mundo feliz estaban los otros, los que sobreviven o mueren en el lado oscuro. «Tienes mucho que hacer, de modo que deja de compadecerte, toma agua y empieza a escribir», dijo Clara a su nieta antes de desaparecer tal como habia llegado (ALLENDE, 2015, p. 434).

A escrita não corresponde a uma mera necessidade pessoal da vida de alguém. Ela é a maneira de contar as histórias e relatos de quem sobrevive, para que outras pessoas possam viver essas histórias, não que se tenha de passar por aquelas experiências. A escrita dos momentos da existência de Clara converte-se em uma maneira de registrar as memórias e as vivências de uma familia excêntrica e alheia ao modelo preestabelecido, passando a ter outro valor ao tornar possivel a reconstrução de futuros, de possibilidades, de alternativas para escolher a vida e seu milagre ao invés das más lembranças das adversidades. É dessa maneira que a escrita se coloca para Alba, pois "Ana Díaz consiguió un cuaderno escolar y me lo regaló. - Para que escribas, a ver si sacas de dentro lo que te está pudriendo, te mejoras de una vez y cantas con nosotras y nos ayudas a coser - me dijo" (ALLENDE, 2015, p. 447). O canto, assim como a escritura, era o que podia permitir a resistência:

Las mujeres se pasaban el día cantando a voz en cuello. Los carabineros les golpeaban la pared. - iCállense, putas! - iHáganos callar, si pueden, cabrones, a ver si se atreven! $-y$ seguian cantando más fuerte y ellos no entraban, porque habian aprendido que no se puede evitar lo inevitable (ALLENDE, 2015, p. 448).

Não se pode evitar o inevitável. É por esse motivo que Clara se casa com Esteban. É por essa razão que Blanca se apaixona por Pedro, amor impossivel que o pai nunca permitiria. É essa circunstância que ocorre com Alba, ainda que uma das irmãs Mora tenha previsto o cruel destino da neta da grande amiga. Não se evita o inevitável, mas se aprende e se constitui por ele, reconstrói-se, criam-se raizes identitárias. La casa de los espiritus evidencia isso tudo, por meio da narração dos destinos dessas três mulheres.

Alba tem nas mãos o destino de construir a sua realidade, após tudo ser destruido. Orienta o leitor: "mi abuelo tuvo la idea de que escribiéramos esta historia. -Asi podrás llevarte las raíces contigo si algún día tienes que irte de aqui, hijita —dijo" (ALLENDE, 2015, p. 451). A vontade de elaborar a violência sofrida e poder seguir adiante em outro lugar é uma aposta, mas a única certeza que garante a necessidade de se levantar é pela escrita da memória de sua família.

A narrativa dessa história foi uma forma de herança que Esteban queria presentear à neta. Contar a história da familia é contar-se a si mesmo, poder reviver a vida como em um filme, poder se perdoar do que tenha feito:

\begin{abstract}
Empecé a escribir con la ayuda de mi abuelo, cuya memoria permaneció intacta hasta el Último instante de sus noventa años. De su puño y letra escribió varias páginas y cuando consideró que lo había dicho todo, se acostó en la cama de Clara. Yo me senté a su lado a esperar con él y la muerte no tardó en llegarle apaciblemente, sorprendiéndolo en el sueño. Tal vez soñaba que era su mujer quien le acariciaba la mano y lo besaba en la frente, porque en los últimos dias ella no lo abandonó ni un instante, lo seguía por la casa, lo espiaba por encima del hombro cuando leía en la biblioteca y se acostaba con él en la noche, con su hermosa cabeza coronada de rizos apoyada en su hombro. Al principio era un halo misterioso, pero a medida que mi abuelo fue perdiendo para siempre la rabia que lo atormentó durante toda su existencia, ella apareció tal como era en sus mejores tiempos, riéndose con todos sus dientes y alborotando a los espíritus con su vuelo fugaz. También nos ayudó a escribir y gracias a su presencia, Esteban Trueba pudo morir feliz murmurando su nombre, Clara, clarisima, clarividente (ALLENDE, 2015, p. 452).
\end{abstract}

A experiência que a escrita nos possibilita faz com que as histórias que narramos passem a ser nossas, mesmo que não as tenhamos vivido. Alba diz: "en algunos momentos tengo la sensación de que esto ya lo he vivido y que he escrito estas mismas palabras, pero comprendo que no soy yo, sino otra mujer, que anotó en sus cuadernos para que yo me sirviera de ellos" (ALLENDE, 2015. p. 453). Essa sensação tem a ver com a narrativa que a avó anotou e que foi transferida a ela não só como memória, mas também como herança:

escribo, ella escribió, que la memoria es frágil y el transcurso de una vida es muy breve y sucede todo tan deprisa, que no alcanzamos a ver la relación entre los acontecimientos, no podemos 
medir la consecuencia de los actos, creemos en la ficción del tiempo, en el presente, el pasado y el futuro, pero puede ser también que todo ocurre simultáneamente (ALLENDE, 2015, p. 453).

A escrita burla a memória, apagada pelo tempo ou pelas dores. Ela reforça nossas necessidades, desfaz nossas violências, transpõe os artificios das realidades que se vive. Alba escreve que todos os rastros deixados pelas escrituras da família estão a serviço do seu ideal, de seu protagonismo:

Quiero pensar que mi oficio es la vida y que mi misión no es prolongar el odio, sino sólo llenar estas páginas mientras espero el regreso de Miguel, mientras entierro a mi abuelo que ahora descansa a mi lado en este cuarto, mientras aguardo que lleguen tiempos mejores, gestando a la criatura que tengo en el vientre, hija de tantas violaciones, o tal vez hija de Miguel pero sobre todo hija mía (ALLENDE, 2015, p. 453).

Alba registra sua história por meio do que sua avó escreveu, durante cinquenta anos, em seus "cadernos de anotar a vida". Os cadernos, todos, "los tengo aquí, a mis pies, atados con cintas de colores, separados por acontecimientos y no por orden cronológico, tal como ella los dejó antes de irse" (ALLENDE, 2015, p. 453-454). A escrita de Clara serve "para rescatar las cosas del pasado y sobrevivir a mi propio espanto" (ALLENDE, 2015. p. 454), para entender a si mesma, a sua familia, a sua origem e descendência. Mas, em suma, para reconstruir-se, para que não se esqueça, mas para que se tenha esperança: "El primero es un cuaderno escolar de veinte hojas, escrito con una delicada caligrafía infantil. Comienza asi:: «Barrabás llegó a la familia por vía marítima..."(ALLENDE, 2015. p. 454). Porque os finais, bem como os começos, são cíclicos, sempre se encontram, mesmo que para se possam afastar. Mas sempre se encontram.

\section{Considerações finais: uma questão de escrita}

A escritura forma e é formada pela nova população mestiça que na América se forma. É a palavra registrada que tem poder de configurar novas instâncias sociais, novas construções históricas, novos conceitos identitários. E foi por meio da literatura a possibilidade de se registrare, por nós, compreender todos os outros mundos possiveis. Em se tratando especificamente da literatura latinoamericana, a realidade social sempre esteve atrelada às linhas ficcionais, tendo as narrativas literárias um papel fundamental de construção cultural.

Para Cristina Ferreira-Pinto, "os escritores latino-americanos têm constantemente produzido uma literatura profundamente engajada com a realidade sócio-política de seus paises" (FERREIRA-PINTO, 1997, p. 81). As desigualdades econômicas e as configurações raciais e étnicas dessa "terra de contrastes" viabilizam uma literatura que expressa o social como elemento norteador e potencializador dos discursos. Esse tipo de "literatura urgente", atua, de um lado, por conta do "meio cultural, político e socioeconômico do autor", e, de outro, pela "tomada de consciência do escritor como tal, isto é, como individuo que escreve, dentro desse meio" (FERREIRA-PINTO, 1997, p. 81). Ao passo que é fruto de um "compromisso de retratar, estudar e, frequentemente, denunciar a realidade social e politica de seus paises" (FERREIRA-PINTO, 1997. p. 81), a literatura é mecanismo que se coloca no compromisso de registro da realidade social, interferindo e tensionando as produções.

Como exemplo, Ferreira-Pinto evidencia que os sistemas repressivos das ditaduras das Américas atuavam na forma como os fatos históricos eram contados, e a ficção se tornou a possibilidade para que os registros de memórias coletivas fossem possiveis. A tensão entre sistema social opressore sujeito que escreve é uma característica também na produção latino-americana das mulheres, uma vez que "a história pessoal do sujeito feminino questiona a história da comunidade e, através do próprio ato narrativo, se empenha em um processo de autoanálise que é no mesmo tempo uma análise histórica, já que a 'História' com H maiúsculo se encontra enredado na história" (FERREIRA-PINTO, 1997, p. 84).

A compreensão da escritura feminina como um elemento que questiona a história oficial é algo que justifica a intencionalidade de movimentos de leitura e formação de leitores de escritoras. O campo literário também é palco de tensões, e 
as lutas que se trava também estão associadas a quem pode e quem não pode circular nesse meio, afinal, "são essas vozes, que se encontram nas margens do campo literário, cuja legitimidade para produzir literatura é permanentemente posta em questão" (DALCASTAGNĖ, 2012, p. 12). Por esse motivo, a adoção de um corpus de produções narrativas femininas se coloca como a necessidade de reconhecimento da identidade latino-americana por meio dos discursos não oficiais, de vozes periféricas e das urgentes discussões de lugares de fala e diversidades, tão comuns nos dias de hoje.

A escrita contemporânea produzida pelas mulheres representa, duplamente, o papel de figuração da mulher e de sua visibilidade em espaços de poder, tanto em suas personagens quanto na própria postura da escritora como ativista politica. Nesse campo de sentido, as autoras evidenciam o habitus distinto feminino ao entregarem-se à produção literária, dominada por homens. É através da palavra que a formulação de uma realidade, seja ela possivel, ainda que utópica, ou realística, e violenta, pode surgir e significar.

Por essa perspectiva, o capital simbólico produzido pelas obras femininas corresponde a um caminho, estreito, de liberdade feminina, mas que ainda sim se sustém em função de que é parte de uma cultura, a literatura. As escritoras, portanto, estabelecem o sentido da literatura como valor simbólico de uma possibilidade da realidade social cuja realização, por vezes negada em função da posição que ocupam, a própria autoria busca em sua vida. Gioconda Belli, escritora nicaraguense, por exemplo, diz que há uma crise da imaginação, e pensar nisso corrobora a tese de uma realidade material e superficial, em que as relações emocionais dão espaço ao instantâneo e ao espaço virtual. Vivemos presos às tecnologias, e já o espaço de sonhar se desfez em meio às necessidades do vencer o tempo em nosso cotidiano.

Por outro lado, a dupla posição de escrita e do feminino desperta a equívoca interpretação de ser uma escrita de/para mulheres, como se esse sentido de interpretação fosse antes um elemento depreciativo de uma literatura menor. Na ânsia pelo vencer e ultrapassar velhos paradigmas, a escritura produzida pelas mulheres latino-americanas está diretamente relacionada a uma voz diferente, por vezes subjugada, de opressão e de percepção do mundo por vezes pautadas pelo interno, não por estar dentro, mas que se origina do dentro - da casa, da consciência, da opressão - evocando memórias e mostrando outras versões.

No manifesto "Sejamos todos feministas", a escritora nigeriana Chimamanda Adichie fala sobre a importância de nos feminizar, e o quanto é importante a discussão desse tema em nossa sociedade contemporânea, pois também ela percebe a naturalização da moralidade de certas dominações encaradas erroneamente como normativas sociais: "Tenho a impressão de que a palavra 'feminina', como a própria ideia de feminismo, também é limitada por estereótipos". E afirma:

Se repetimos uma coisa várias vezes, ela se
torna normal. Se vemos uma coisa com frequ-
ência, ela se torna normal. Se só os meninos
são escolhidos como monitores de classe,
então em algum momento nós todos vamos
achar, mesmo que inconscientemente, que só
um menino pode ser o monitor da classe. Se
só os homens ocupam cargos de chefia nas
empresas, começamos a achar "normal" que
esses cargos de chefia só sejam ocupados por
homens (ADICHIE, [2014]).

O texto de Isabel Allende assinala outro tipo de escritura, marginaliza-se na prática hegemônica da escritura e transcende a lógica da escrita, que tanto tem se mostrado chegar ao esgotamento. Torna-se um epicentro por isso: é possivel uma nova reescritura da história das mulheres, e essa proposta coloca-se por meio da noção de reescrever novas maneiras de ver o mundo, como fissuras que não só recontam fatos, condições e papéis, mas como transgressões que inauguram linguagens, temas e discursos.

Histórias como as de Isabel Allende, as de testemunho, as de memória, ampliam e democratizam acessos de conhecimento de histórias que não serão mais únicas. Os espaços simbólicos têm sido desnaturalizadamente conquistados, as narrativas têm se ampliado, as escritas devem ser diversas. Porque, cada vez mais, faz-se necessário romper o silêncio. Efetivamente e de uma vez por todas. 


\section{Referências}

ADICHIE, Chimamanda. Sejamos todos feministas. E-book. Disponivel em www.kobobooks.com. Acesso em: 30 set. 2014. https://doi.org/10.14393/cef-v31n1-2018-19

ALLENDE, Isabel. La casa de los espiritus. España: Penguin, 2015. [1982].

DALCASTAGNĖ, Regina. Literatura brasileira contemporânea: um território contestado. Vinhedo: Editora Horizonte; Rio de Janeiro: Editora da Uerj, 2012.

FERREIRA-PINTO, Cristina. Escrita, auto-representação e realidade social no romance feminino latino-americano. Revista de Critica LiterariaLatinoamericana, [S. l.], n. 45, p. 81-95, 1. sem. 1997. https://doi. org/10.2307/4530893

LITERATURA Latino-americana. Revista Bravo!, São Paulo, n. 117, maio 2007.

NAVARRO. Márcia Hoppe. Apresentação. In: NAVARRO. Márcia Hoppe (org.). Rompendo o silêncio: Gênero e literatura na América Latina. Porto Alegre: Editora da Universidade/UFRGS, 1995. p. 09-10.

RICOEUR, Paul. A memória, a história, o esquecimento. Tradução: Alain François [et al.]. Campinas: Editora da UNICAMP, 2007

SHAW, Donald L. La narrativa testimonial y el posboom. In: SHAW, Donald L. Nueva Narrativa Hispanoamericana: Boom, Posboom, Posmodernismo. 6. ed. Madrid: Cátedra, 1999. p. 253-276.

\section{Endereço para correspondência}

Amanda da Silva Oliveira

Av. Roraima, 1000, Cidade Universitária, Prédio 40A, Sala 2307

Camobi 97105-900

Santa Maria, RS, Brasil

\section{Amanda da Silva Oliveira}

Graduada em Letras Português/Espanhol e Respectivas Literaturas pela Universidade Feevale (FEEVALE) e em Ciências Sociais pela Universidade Federal do Rio Grande do Sul (UFRGS). Especialista em Literatura Brasileira pela Universidade Federal do Rio Grande do Sul (UFRGS). Mestre e Doutora em Teoria da Literatura pela Pontificia Universidade Católica do Rio Grande do Sul (PUCRS). Atualmente, é Professora Adjunta do Departamento de Letras Estrangeiras Modernas da Universidade Federal de Santa Maria (UFSM), onde desenvolve estudos nas áreas de ensino de língua estrangeira, lingua espanhola, e no projeto de pesquisa "A literatura como ferramenta no ensino de língua espanhola". 